Original Article

\title{
Effects of the ankle angle of an ankle foot orthosis on foot pressure during the gait in healthy adults
}

\author{
Jong-Sung Chang, PT, PhD ${ }^{1)}$, Hae-Yong Lee, PT, MS ${ }^{2)}$, Myoung-Kwon Kim, PT, PhD ${ }^{3)^{*}}$ \\ 1) Department of Physical Therapy, Yeungnam University College, Republic of Korea \\ 2) Department of Physical Therapy, College of Rehabilitation Science, Daegu University, Republic of \\ Korea \\ 3) Department of Physical Therapy, College of Rehabilitation Science, Daegu University: \\ 201 Daegudae-ro, Gyeongsan-si, Gyeongsangbuk-do, Republic of Korea
}

\begin{abstract}
Purpose] The purpose of this study was to investigate the effects of the ankle angle of an ankle foot orthosis (AFO) on foot pressure during the gait in healthy adults. [Subjects] Sixteen healthy males with neither orthopedic nor neurological problems participated in this study. [Methods] Subjects walked on a walkway at a self-selected pace with an AFO set at four different ankle angles $\left(-5^{\circ}, 0^{\circ}, 5^{\circ}\right.$, and $\left.10^{\circ}\right)$. Foot pressure was measured randomly according to the ankle angle of the AFO using an F-scan system. Three trials were measured and averaged for data analysis. [Results] The peak foot pressure of the hallux, 2nd-5th toes, 2nd and 3rd metatarsal heads, 4th and 5th metatarsal heads, and the heel showed significant differences among the AFO ankle angles: angles of $0^{\circ}$ and $-5^{\circ}$ increased the foot pressure of the lateral legions, and the peak foot pressure of the heel at an AFO ankle angle of $10^{\circ}$ was significantly greater than those of the other angles. [Conclusion] The ankle angle of the AFO affected foot pressure and gait patterns during gait. The results suggest that the appropriate angle for an AFO is between $5^{\circ}$ and $10^{\circ}$ when AFOs are prescribed by clinicians.
\end{abstract}

Key words: Ankle foot orthosis, Ankle angle, Gait

(This article was submitted Oct. 8, 2014, and was accepted Nov. 28, 2014)

\section{INTRODUCTION}

Following stroke, impairments of balance control and gait are major problems for stroke patients, and they restrict activities of daily living and postural control. Stroke patients often have impaired ankle function due to muscle weakness and increased spasticity ${ }^{1-3)}$. In addition, ankle instability caused by compression of the deep peroneal, sprained ankles, and excessive joint mobility also cause dysfunctions of balance control and gait ${ }^{4,5)}$.

Ankle foot orthoses (AFOs) are usually suggested to compensate for impairments of the central nervous system, ankle instability, muscle weakness, and proprioceptive deficits at the ankle joint ${ }^{6-8)}$. AFOs are prescribed to improve the stability of the ankle joint and gait speed, to reduce energy consumption during gait, and to maintain balance ability, and AFOs are also used to improve the abnormal gaits of stroke patients and to prevent excessive equinovarus during gait $^{5,9-11)}$.

AFOs prevent foot drop and the dragging of the toes during the swing phase by supporting dorsiflexion and limiting

*Corresponding author. Myoung-Kwon Kim (E-mail: skybird-98@hanmail.net)

(C2015 The Society of Physical Therapy Science. Published by IPEC Inc. This is an open-access article distributed under the terms of the Creative Commons Attribution Non-Commercial No Derivatives (by-ncnd) License $<$ http://creativecommons.org/licenses/by-nc-nd/3.0/> . plantar flexion, as well as by facilitating heel contact and mediolateral stability ${ }^{12)}$. Studies of postural stability and balance according to features and materials of AFOs do exist; however, studies related to the effects of ankle joint angles of AFOs on gait have not been performed in clinical studies. This study investigated the effects of the ankle angle of an AFO on foot pressure during the gait in healthy adults.

\section{SUBJECTS AND METHODS}

Sixteen healthy males (age: $26.1 \pm 1.2$ years, height: $174.2 \pm 4.1 \mathrm{~cm}$, weight: $71.6 \pm 2.2 \mathrm{~kg}$, foot length: $267.2 \pm 1.8 \mathrm{~mm}$ ) participated in this study. They had no orthopedic problems, such as osteoarthritis or fractures, and no neurological problems. All the participants received sufficient explanation of the purposes of the trial, and they gave their written informed consent to participation in this study. The study protocol was approved by the Institutional Review Board for Human Research and conformed to the ethical principles of the Declaration of Helsinki.

The ankle joint angle was manipulated using AFOs manufactured with four kinds of inclinations: the neutral position $\left(0^{\circ}\right), 5^{\circ}$ of dorsiflexion $\left(5^{\circ}\right), 10^{\circ}$ of dorsiflexion $\left(10^{\circ}\right)$, and $5^{\circ}$ of plantarflexion $\left(-5^{\circ}\right)$. The ankle joint angle was measured randomly to avoid the effects of learning. The experimental procedure was explained to participants before measurement in order to accurately measure foot plantar pressure, and the subjects practiced walking with an AFO for one-minute. After practicing, the F-scan was calibrated according to 
Table 1. Changes of foot pressure with the ankle angle of an $\mathrm{AFO}\left(\mathrm{N} / \mathrm{cm}^{2}\right)$

\begin{tabular}{lcccc}
\hline & 0 & 5 & 10 & -5 \\
\hline Hallux* & $253.8 \pm 47.2^{\mathrm{a}}$ & $271.9 \pm 40.2^{\mathrm{a}}$ & $277.1 \pm 74.8^{\mathrm{a}}$ & $214.9 \pm 49.0^{\mathrm{b}}$ \\
2-5th toes* & $103.3 \pm 17.7^{\mathrm{a}}$ & $89.9 \pm 29.6^{\mathrm{b}}$ & $84.6 \pm 13.8^{\mathrm{b}}$ & $102.1 \pm 16.5^{\mathrm{a}}$ \\
1st metatarsal head & $387.4 \pm 84.0$ & $350.1 \pm 89.6$ & $345.5 \pm 64.4^{\mathrm{a}}$ & $387.1 \pm 64.9$ \\
2nd \& 3rd metatarsal head* & $401.6 \pm 64.8^{\mathrm{a}}$ & $432.3 \pm 60.4^{\mathrm{b}}$ & $450.4 \pm 48.4^{\mathrm{b}}$ & $321.2 \pm 45.2^{\mathrm{c}}$ \\
4th \& 5th metatarsal head* & $94.8 \pm 32.4^{\mathrm{a}}$ & $78.4 \pm 25.9^{\mathrm{b}}$ & $69.3 \pm 21.9^{\mathrm{b}}$ & $102.3 \pm 16.3^{\mathrm{a}}$ \\
Midfoot & $53.1 \pm 18.5$ & $47.9 \pm 21.1$ & $54.4 \pm 22.6$ & $51.4 \pm 16.7$ \\
Calcaneal region* & $240.3 \pm 48.3^{\mathrm{a}}$ & $260.9 \pm 44.4^{\mathrm{a}}$ & $291.6 \pm 42.5^{\mathrm{b}}$ & $246.1 \pm 37.9^{\mathrm{a}}$ \\
\hline
\end{tabular}

All values are the mean \pm SD. The values with different superscripts in the same column are significantly different at the $\mathrm{p}<0.05$ level according to Tukey's post hoc test.

the manufacturer's protocol for one second. The subjects were asked to walk several times as naturally and directly as possible while looking straight ahead. Foot pressure was measured using a matrix-shaped F-scan system (Tekscan, USA) during gait ${ }^{13)}$. The $\mathrm{F}$-scan incorporates a grid of 960 force and pressure sensors beneath the entire plantar surface of the foot. The ultrathin film insole containing the sensors was trimmed to each subject's AFO size before insertion.

The recorded pressures of each pressure sensor were transmitted to a personal computer and were sampled at 60 frames/sec using the Teckscan program. Foot pressure was analyzed using pressure measurement system after separating the data of the different plantar areas. For foot plantar pressure measurement, the plantar regions were divided into seven distinct regions: the hallux, 2nd-5th toes, $1 \mathrm{st}$ metatarsal head, 2nd and 3rd metatarsal heads, 4th and 5th metatarsal heads, midfoot, and the heel region.

The data of the peak foot pressure was collected for each foot region. Once natural walking of the participants was confirmed, the data from the middle 5 seconds of gait were used in the analysis because the participants were blind to the measured time. Three trials were measured and then averaged for data analysis. The mean value of the peak pressure of each region was calculated after measuring the foot pressure using the F-scan research 5.83 program. One minute of rest was provided between measurements, and five minutes of rest was provided between the wearing of the orthoses with different ankle angles.

All data were normally distributed according to the Kolmogorov-Smirnov test. One-way repeated measures ANOVA was performed to compare the differences in foot pressure, and Tukey's post-hoc test was used to analyze the differences among the ankle angles using SPSS 18.0. Statistical significance was accepted for values of $p<0.05$ in all analyses.

\section{RESULTS}

The peak foot pressures of the hallux, 2 nd -5 th toes, 2 nd and 3rd metatarsal heads, 4th and 5th metatarsal heads, and the heel showed significant differences among the angles (Table 1) $(\mathrm{p}<0.05)$. The post-hoc test showed that the hallux pressure significantly increased as the ankle angle increased, the pressure of the 2 nd -5 th toes and the 4 th and 5 th metatarsal heads significantly differences between $0^{\circ}$ and $-5^{\circ}$, and $5^{\circ}$ and $10^{\circ}$, and the pressure of the 2 nd and 3rd metatarsal head showed significant differences between the values of $5^{\circ}$ and $10^{\circ}$, and those of $0^{\circ}$ and $-5^{\circ}$. The peak foot pressure of the heel at $10^{\circ}$ was significantly greater than those of the other angles (Table 1) $(\mathrm{p}<0.05)$.

\section{DISCUSSION}

Stroke patients may lack sufficient heel strike, push off, and toe clearance during gait, so AFOs have often been prescribed to improve the stability of the ankle joints in stroke patients with ankle instability, and they are considered a good method for maintaining postural stability ${ }^{14)}$. The purpose of this study was to determine the effect on plantar pressure during walking of AFO with the ankle joint angles usually prescribed for stroke patients: the neutral position $\left(0^{\circ}\right), 5^{\circ}$ of dorsiflexion $\left(5^{\circ}\right), 10^{\circ}$ of dorsiflexion $\left(10^{\circ}\right)$, and $5^{\circ}$ of plantar flexion $\left(-5^{\circ}\right)$.

A normal gait pattern transfers weight after heel contact with the ground by a heel-rocker mechanism using eccentric and concentric contractions of the dorsiflexors. When the heel makes contact, it maintains the center of gravity in the midline with some eversion ${ }^{8,14,15)}$. The results of this study show that the center of pressure moved to the outside at $-5^{\circ}$ in the foot pressure distribution unlike normal gait and body weight support heel side. It is an abnormal movement of the foot considered to be continued, and it shows a similar pattern, but better than $-5^{\circ}$ at $0^{\circ}$. The results of this study confirm that gait has a negative effect on abnormal mechanical movement of the ankle joint.

However, the $5^{\circ}$ and $10^{\circ}$ AFO ankle angles had positive effects on the gait patterns of healthy adults, resulting in transfer of weight from the heel to the hallux (big toe). This result is consistent with the results of Kim and Park ${ }^{11)}$ who reported that during one leg standing with AFOs with different ankle angles, the AFO angles correlated with balance performance, joint stability, and postural control. A previous study demonstrated that appropriate control of the ankle joint elicits an efficient gait pattern and energy consumption during gait, and this was confirmed in the present study by measuring foot pressure ${ }^{1,2,12,16,17)}$.

Taken together these findings indicate that AFOs with appropriate ankle angles are needed to control the stability of the ankle joint and muscle activation. Although a limitation of this study was the recruitment of healthy adults, we 
confirmed that the ankle angles of the AFOs affected foot pressure and gait pattern during gait. The present results suggest that the appropriate angle for AFOs was more than $5^{\circ}$ and $10^{\circ}$ when AFOs are prescribed by clinicians. Further studies will be required to determine the effects of AFO angles on stroke patients and patients with ankle instability.

\section{ACKNOWLEDGEMENT}

This research was supported by the Yeungnam University College Research Grants in 2014.

\section{REFERENCES}

1) Pohl M, Mehrholz J: Immediate effects of an individually designed functional ankle-foot orthosis on stance and gait in hemiparetic patients. Clin Rehabil, 2006, 20: 324-330. [Medline] [CrossRef]

2) Suat E, Fatma U, Nilgün B: The effects of dynamic ankle-foot orthoses on functional ambulation activities, weight bearing and spatio-tempora characteristics of hemiparetic gait. Disabil Rehabil, 2011, 33: 2605-2611. [Medline] [CrossRef]

3) Wang RY, Yen L, Lee CC, et al.: Effects of an ankle-foot orthosis on balance performance in patients with hemiparesis of different durations. Clin Rehabil, 2005, 19: 37-44. [Medline] [CrossRef]

4) Churchill AJ, Halligan PW, Wade DT: Relative contribution of footwear to the efficacy of ankle-foot orthoses. Clin Rehabil, 2003, 17: 553-557. [Medline] [CrossRef]

5) Huang YC, Harbst K, Kotajarvi B, et al.: Effects of ankle-foot orthoses on ankle and foot kinematics in patients with subtalar osteoarthritis. Arch Phys Med Rehabil, 2006, 87: 1131-1136. [Medline] [CrossRef]

6) Chen CK, Hong WH, Chu NK, et al.: Effects of an anterior ankle-foot orthosis on postural stability in stroke patients with hemiplegia. Am J Phys Med Rehabil, 2008, 87: 815-820. [Medline] [CrossRef]

7) Esquenazi A, Ofluoglu D, Hirai B, et al.: The effect of an ankle-foot orthosis on temporal spatial parameters and asymmetry of gait in hemiparetic patients. PM R, 2009, 1: 1014-1018. [Medline] [CrossRef]

8) Gök $\mathrm{H}$, Küçükdeveci A, Altinkaynak $\mathrm{H}$, et al.: Effects of ankle-foot orthoses on hemiparetic gait. Clin Rehabil, 2003, 17: 137-139. [Medline] [CrossRef]

9) Fatone S, Gard SA, Malas BS: Effect of ankle-foot orthosis alignment and foot-plate length on the gait of adults with poststroke hemiplegia. Arch Phys Med Rehabil, 2009, 90: 810-818. [Medline] [CrossRef]

10) Lee Y, Her JG, Choi Y, et al.: Effect of ankle-foot orthosis on lower limb muscle activities and static balance of stroke patients authors' names. J Phys Ther Sci, 2014, 26: 179-182. [Medline] [CrossRef]

11) Kim CS, Park SY: Effects of an ankle foot orthosis with ankle angles on balance performance in healthy adults. J Ergo Soc Korea, 2011, 30: 291296. [CrossRef]

12) Nolan KJ, Savalia KK, Lequerica AH, et al.: Objective assessment of functional ambulation in adults with hemiplegia using ankle foot orthotics after stroke. PM R, 2009, 1: 524-529. [Medline] [CrossRef]

13) Hamid A, Patar M, Ayub MA: Force sensor detection and performance evaluation of new active system ankle foot orthosis. Procedia Eng, 2012, 41: 510-515. [CrossRef]

14) Ohata $K$, Yasui $T$, Tsuboyama $T$, et al.: Effects of an ankle-foot orthosis with oil damper on muscle activity in adults after stroke. Gait Posture, 2011, 33: 102-107. [Medline] [CrossRef]

15) McCormick CJ, Bonanno DR, Landorf KB: The effect of customised and sham foot orthoses on plantar pressures. J Foot Ankle Res, 2013, 6: 19. [Medline] [CrossRef]

16) Haruna H, Sugihara S, Kon K, et al.: Change in the mechanical energy of the body center of mass in hemiplegic gait after continuous use of a plantar flexion resistive ankle-foot orthosis. J Phys Ther Sci, 2013, 25: 1437-1443. [Medline] [CrossRef]

17) Ring H, Treger I, Gruendlinger L, et al.: Neuroprosthesis for footdrop compared with an ankle-foot orthosis: effects on postural control during walking. J Stroke Cerebrovasc Dis, 2009, 18: 41-47. [Medline] [CrossRef] 